\title{
Optimisation of Optical fibre Using Micro-braiding for Structural Health Monitoring
}

DOI:

10.1177/1045389X18810805

\section{Document Version}

Accepted author manuscript

Link to publication record in Manchester Research Explorer

\section{Citation for published version (APA):}

Rufai, O., Gautam, M., Potluri, P., \& Gresil, M. (2018). Optimisation of Optical fibre Using Micro-braiding for Structural Health Monitoring. Journal of Intelligent Material Systems and Structures.

https://doi.org/10.1177/1045389X18810805

\section{Published in:}

Journal of Intelligent Material Systems and Structures

\section{Citing this paper}

Please note that where the full-text provided on Manchester Research Explorer is the Author Accepted Manuscript or Proof version this may differ from the final Published version. If citing, it is advised that you check and use the publisher's definitive version.

\section{General rights}

Copyright and moral rights for the publications made accessible in the Research Explorer are retained by the authors and/or other copyright owners and it is a condition of accessing publications that users recognise and abide by the legal requirements associated with these rights.

\section{Takedown policy}

If you believe that this document breaches copyright please refer to the University of Manchester's Takedown Procedures [http://man.ac.uk/04Y6Bo] or contact uml.scholarlycommunications@manchester.ac.uk providing relevant details, so we can investigate your claim.

\section{OPEN ACCESS}


Journal of Intelligent Material Systems \& Structures

\section{Optimisation of Optical fibre Using Micro-braiding for Structural Health Monitoring}

\begin{tabular}{|c|c|}
\hline Journal: & Journal of Intelligent Material Systems and Structures \\
\hline Manuscript ID & JIM-18-165.R2 \\
\hline Manuscript Types: & Original Article \\
\hline Date Submitted by the Author: & 20-Sep-2018 \\
\hline Complete List of Authors: & $\begin{array}{l}\text { Rufai, Olubukola; The University of Mancheter, i-Composites Lab, } \\
\text { Northwest Composite Centre, School of Materials } \\
\text { Gautam, Mayank; The University of Mancheter, Robotics \& Textile } \\
\text { Composite Group, Northwest Composite Centre, School of Materials } \\
\text { Potluri, Prasad; The University of Manchester, Robotics \& Textile Composite } \\
\text { Group, Northwest Composite Centre, School of Materials } \\
\text { Gresil, Matthieu; The University of Manchester, i-Composites Lab, } \\
\text { Northwest Composite Centre, School of Materials }\end{array}$ \\
\hline Keyword: & $\begin{array}{l}\text { Structural Health Monitoring, Sensor, Fiber optics, Micro-braiding, Braid } \\
\text { Angle, Fibre Bragg Grating }\end{array}$ \\
\hline Abstract: & $\begin{array}{l}\text { Structural health monitoring (SHM) is a fast growing area used to assess } \\
\text { the state of various structures such as; aircraft, building, bridge, wind } \\
\text { turbine, pipe, automobile through appropriate data processing and } \\
\text { interpretation. This paper presents a novel technique of optimising the } \\
\text { conventional optical fibres (OF) used for SHM, in order to improve their } \\
\text { mechanical properties, and handling during the manufacturing process by } \\
\text { micro-braiding the OF. This study investigates and compares the tensile } \\
\text { properties of the both micro-braided optical fibre (MBOF) and conventional } \\
\text { OF through uniaxial tensile tests. Experimental results show } 85 \% \\
\text { improvement in strain at failure for the MBOF compare to the OF. } \\
\text { Moreover, interfacial shear strength (IFSS) comparison, of the braiding } \\
\text { yarn (BY), between OF and MBOF (carried out through micro-bond test) } \\
\text { has also been conducted. In addition, the effect of embedding both micro- } \\
\text { braided and conventional optical fibre in composite was also investigated } \\
\text { by three point bend test. Overall the mechanical performance of the } \\
\text { composite was not affected by the presence of MBOF. This paper will also } \\
\text { discuss the process and the advantage of micro-braided optical fibre for } \\
\text { structural health monitoring. }\end{array}$ \\
\hline
\end{tabular}




\title{
Optimisation of Optical fibre Using Micro-braiding for Structural Health Monitoring
}

\author{
Olubukola Rufai ${ }^{1}$, Mayank Gautam ${ }^{2}$, Prasad Potluri $^{2}$, Matthieu Gresil $^{1, *}$
}

\begin{abstract}
Structural health monitoring (SHM) is a fast growing area used to assess the state of various structures such as; aircraft, building, bridge, wind turbine, pipe, automobile through appropriate data processing and interpretation. This paper presents a novel technique of optimising the conventional optical fibres (OF) used for SHM, in order to improve their mechanical properties, and handling during the manufacturing process by micro-braiding the OF. This study investigates and compares the tensile properties of the both micro-braided optical fibre (MBOF) and conventional OF through uniaxial tensile tests. Experimental results show $85 \%$ improvement in strain at failure for the MBOF compare to the OF. Moreover, interfacial shear strength (IFSS) comparison, of the braiding yarn (BY), between OF and MBOF (carried out through micro-bond test) has also been conducted. In addition, the effect of embedding both micro-braided and conventional optical fibre in composite was also investigated by three point bend test. Overall the mechanical performance of the composite was not affected by the presence of MBOF. This paper will also discuss the process and the advantage of micro-braided optical fibre for structural health monitoring.
\end{abstract}

\section{Keywords}

Structural health monitoring, composites, micro-braided optical fibre, conventional optical fibre, braid angle

\section{Introduction}

Structural health monitoring (SHM) is a fast growing sector in engineering applications especially in the aerospace industry. Available practical experience has proved that continuous improvement of the sensing techniques will accelerate the growth of SHM technology.

\footnotetext{
i-Composites Lab, Northwest Composite Centre, School of Materials, University of Manchester, UK;

2 Robotics \& Textile Composite Group, Northwest Composite Centre, School of Materials, University of Manchester, UK

Corresponding Author: Matthieu Gresil, i-Composites Lab, Northwest Composite Centre, School of Materials, University of Manchester, UK.

Email: matthieu.gresil@manchester.ac.uk
}

Optical fibres are used for detecting damage in composite structures due to their light weight, size and immunity to electromagnetic interference (Takeda et al., 2002; Guemes et al., 2010). SHM has been developed to study and track the operating behaviour of a component in real time to detect operational anomalies and identify any existent damage, predict further 
behaviour and estimate the remaining service life. SHM requires the use of online sensing techniques to provide continuous assessment of engineering structures such as aircraft, automobiles, building, train and bridges. Dynamic response such as strain, vibration deformation and displacement should be monitored to identify early signs of failure before it happens (Hamouda et al., 2010).

Available practical experience has proven that continuous improvement of the sensing techniques will further accelerate the growth of SHM technology. Optical fibres are used for monitoring manufacture and detecting damage in composite structures due to their size and light weight (Tsuda et al., 2004; Takeda et al., 2002; Takeda et al., 2005b; Takeda et al., 2003; Takeda et al., 2005a; Sanchez et al., 2015; Chandarana et al., 2017; Costa et al., 2016; Tsuda, 2006). Different optical fibre exist such as distributed optical sensors, fabry-perot sensors, mach-zehnder sensors, fibre bragg grating (FBG) sensors etc. The main advantages of FBG sensors over other optical fibre sensors are its low cost, good linearity, availability of wavelength multiplexing and elimination of transduction mechanism which is available in interferometric sensors. However, these optical fibres have the disadvantage of being brittle and easy to break at low strain of $<0.8 \%$, this makes their handling very difficult. Principle of operation of a fibre bragg grating (FBG) is based on periodic change in the refractive index of the core. This causes reflection when light is at a particular wavelength called the Bragg wavelength $\left(\lambda_{B}\right)$ while other light is transmitted. Bragg wavelength is dependent on the FBG's grating period $(\Lambda)$ and effective refractive index of the fibre core $\left(\mathrm{n}_{\text {eff }}\right)$. When an FBG is strained along the fibre axis, the Bragg grating stretches or contracts, causing $\Lambda$ and $n_{\text {eff }}$ to increase or decrease. This produces an increase or decrease in $\lambda_{\mathrm{B}}$ directly relative to $\Lambda$ and $\mathrm{n}_{\text {eff }}$ as represented in Equation 1 (Tsuda, 2006).

$\lambda=2 n_{e f f} \Lambda$

When maintaining a constant temperature in experiment, the strain on the FBG can be determined using Equation 2.

$\left(\frac{\Delta \lambda_{B}}{\lambda_{B}}\right)=\kappa \Delta \varepsilon$

Where $\Delta \lambda_{B}$ is the change in Bragg wavelength, $\lambda_{B}$ is the unstrained Bragg wavelength and $\kappa$ is the FBG strain gage factor. The theoretical value for $\kappa$ for pure silica glass is 0.78 (Kreuzer). In this study, braiding will be used to improve the handling and mechanical properties of conventional optical fibre (OF). Braiding is a textile forming technique which involves interlacement of three or more yarns/tows, such that each set of yarn form a well-defined interlaced pattern at a biased angle following a helical path. Braided structure are desirable because of their structural integrity, design flexibility, durability, precision, cost effectiveness, robustness of the manufacturing process, high level of compatibility, damage resistance and ability to reinforce shaped parts (Sree Shankhachur and Potluri, 2016; 
Brunnschweiler, 1953; Tate et al., 2006; Lee et al., 1999; Milwich et al., 1995). Also their architecture can be categorised into bi-axial and tri-axial according to the orientation of constituent strands. In general, both types of braids have two sets of strands place in the clockwise and anti-clockwise direction, whereas tri-axial braids also have additional set of strand in the axial direction. However, significant tow crimp may be produced during braid manufacture. This crimp emerges from the braid architecture due to undulation of a tow as a result of interlacement between tows. Braided structures have been used for critical applications from rocket launchers, automotive part, aircraft structures to textile structures such as: ropes, shoelaces, sutures, sporting goods.

(Heieck et al., 2017) studied the effect of cover-factor on the mechanical properties of biaxial and triaxial braided carbon fibre composite. Results showed that cover factor has effect on the mechanical property of the braided composite, depending on the type of braid and testing direction. (Omeroglu, 2006) studied the effect of braid parameters on the mechanical properties of braided ropes. He investigated the effect of varying the braid pattern and take up speed on the mechanical property of braided rope of polypropylene. He discovered that highest values for maximum strain and yield strain were obtained with the low take-up rate and the $1 / 1$ pattern. However, the highest values for maximum tenacity, modulus and yield tenacity were obtained with the high take-up rate and the $2 / 2$ pattern. (Del Rosso et al., 2015) (21) investigated the mechanical properties of dry micro-braids and micro-braid reinforced polymer composite. Effect of different braid architectures, number of braided yarns and braid angles were assessed through a series of tensile tests on dry micro-braids using two different yarns. He observed that the final mechanical properties of the micro-braids depend not only on the material property but also on the braid angle and architecture. As the braid angle increased, also the strain at failure increases.

(Hufenbach et al., 2014) developed and implemented an online monitoring of composite structures by integrating automatically the optical fibre sensors. Influence of manufacturing parameter on the mechanical property of the composite structure was evaluated. (Hamouda et al., 2015) evaluated the integrity of 3D orthogonal woven composite embedded with polymer optical fibre They show that the integrity of 3D woven composite was not affected by the presence of polymer optical fibre. (Yuan et al., 2004) measured the internal strain of 3D braided composites using co-braided optical fibre sensors. Results showed that optical sensor can be braided into composites to measure internal parameters.

Through the literature review conducted, limited or no studies have been reported present with reference to improving the handling and mechanical properties of optical fibres (Rufai et al.). The primary aim of this study is to investigate the potential of optimising optical fibre through textile manufacturing process of braiding. The optimisation will be achieved through a novel process of micro-braiding. Mechanical and handling properties of the micro-braided optical fibre will be studied to determine the effect of micro-braiding on the optical fibre. 


\section{Materials, Manufacture \& Test Methodology}

\section{Materials}

Fibre Bragg grating (FBG) sensors manufactured by AtGrating Technologies have been used in this study. The Scanning electron micrograph in Figure 1 shows that the diameter is $150 \pm 4$ $\mu \mathrm{m}$. In order to micro-braid this optical fibre, a $33 \mathrm{Tex}$ S-glass tow with filament diameter of $9 \mu \mathrm{m}$ with density of $2.53 \mathrm{~g} / \mathrm{cm}^{3}$ was used (Agy; PriceEngineering). Tensile properties of the S glass tow was measured experimentally following the standard (ISO, 2062:1995). A total of 9 specimens were tested at a strain rate of $250 \mathrm{~mm} / \mathrm{min}$. The tows were clamped using a special gripping system present at both ends. This gripping system consisted of two pneumatic action grips two parts as shown in Figure 2. The fibre tows were wrapped (3 turns) in the first part and then the two parts were closed using pneumatics, locking the wrapped tow in its position. The Young's modulus was found to be: $61 \pm 2 \mathrm{GPa}$ and the tensile strength was found to be: $1663 \pm 230 \mathrm{MPa}$. An optical sensing interrogator (Micron-Optics sm-125) and Micron Optics ENLIGHT software were used to record the reflection spectrum of the FBG sensor.

\section{[Insert Figure 1]}

[Insert Figure 2]

The FBG sensor was braided using the Cobra 450 maypole braiding machine with 12 horn gears, equipped with 24 carriers. However, only four carriers were used to braid the optical fibres, as shown in Figure 3a, since use of more than 4 carriers resulted in producing a braid that had a looser grip on the optical fibre. Higher number of carriers resulted in braid diameter (braid with no core) becoming higher than the optical fibre. Moreover, the topology of a braid is dependent upon the number of bobbins and choice of the location of the carriers on the braiding machine. Schematic of the micro-braiding setup is shown in Figure $3 \mathrm{~b}$. The use of 4 carriers (specifically chosen) on the 24 carrier braiding machine resulted in formation of a diamond braid (1/1 topology) as shown in the schematic image in Figure 3c. If a tow continuously passes over one tow and then under one tow of the opposing group, it is called a 1/1 braid or a diamond braid (Nawaz et al., 2013). The use of four bobbins also resulted in a complete braid coverage of the optical fibre.

\section{[Insert Figure 3]}

The bobbins that feed the yarn/tows were mounted on the selected carriers, and were wound with 33 Tex, S-glass tow. A Tex can be defined as the weight of yarn/tow with a length of $1 \mathrm{~km}$, and is commonly used to express linear density of yarn/tow. A uniform yarn/tow feed tension of $150 \mathrm{~g}$ was kept constant for all carriers, to keep the yarn/tows under tension to avoid non-uniform braid formation, as the tows will be slack at very low carrier tension. For the production of the micro-braid with the given set-up, ultra-high molecular weight 


\section{Micro-bond Test}

polyethylene (DSM ${ }^{\circledR}$ Dyneema) was bonded to one end of the optical fibre before passing it through the tension device and through the centre of the braiding machine. The other end of the optical fibre was then taped to the device to hold it in place. This was followed by braiding a few millimetres over the optical fibre till the braid reached its convergence point. At a convergence point, a stable and uniform formation of braid occurs.

During the braiding process, fibre breakage or splitting of the filaments with the tow (also referred to as filamentation) can occur, which is often a result of winding process or the passing of the tow through multiple contact points on the carrier of the machine. An optimum take-up speed to machine speed ratio was chosen to assure stable braid formation occurs; this ratio resulted in braiding a metre of optical fibre in $25 \pm 9$ mins. The lowest possible optimum braid take-up speed resulted in high processesing times ( 6 hours per a metre length of braid). A very high speed resulted in non-uniform braid formation. The braid angle was determined through several trials experimentally. Braid angle between $16-17^{\circ}$ was achieved at optimum takeup speed to machine speed. Relationship between take up speed and machine speed in determining braid angle as been discussed by (Potluri et al., 2003). This experimental braid angle was the optimum braid angle resulting almost in full coverage of the braid over the optical fibre.

Micro-bond samples were prepared using individual fibres from S-glass tow, conventional optical fibre and micro-braided optical fibre which were bonded to a cardboard tab. No standard way of preparing samples for micro-bond test have been reported in literature. However, different technique has been developed by researchers (Favre and Merienne, 1981; Wang et al., 2013; Yang and Thomason, 2010; M, 2008; Nishikawa et al., 2008). Mixture of epoxy resin Araldite LY564 supplied by Huntsman and hardener Aradur 2954 supplied by Mouldlife were deposited on the fibre using strands of each fibre and cured in the oven at $80^{\circ}$ for 5 hours (Huntsman, 2010). The samples were heated to $80^{\circ}$ (glass-transition temperature) because the cardboard tab could not be heated to higher temperature. Only fibres with symmetrical resin droplet were used for this test. This is important in order to avoid huge variation in the calculated IFSS. Embedded length, droplet area, and fibre diameter were measured using microscopic images as shown in Figure 4. During the micro-bond test, some samples experienced sliding of resin from the fibre and breakage of fibre instead of debonding of the resin from the matrix. Data from these samples were discarded. Only debonding samples were used in this analysis. The de-bonding force has been plotted against the embedded area as shown in Figure 17. Average value of the measured parameters is shown in Table 1. The difference in the embedded length between samples is due to difference in their diameter. As seen in Table 1, embedded length increased as sample diameter increased. Taking the braiding yarn (BY) for example, resin droplet was made by using a strand of the BY fibre to make droplet on the BY sample; this method was also used 
for the $\mathrm{OF}$ and MBOF using fibres of the OF and MBOF. Higher diameter of fibre absorbs more resin droplet to cover the fibre diameter completely (Carroll, 1976; Favre and Merienne, 1981; Gholami et al., 2017; Yang and Thomason, 2010; Miller et al., 1991). It has been reported in (Rong et al., 2001; Wang et al., 2014) that variation in IFSS data for fibres is influenced by factors such as fibre diameter, embedded length, surface morphology and quality of the prepared samples for the test. (Wang et al., 2014) reported variation of $4 \mathrm{MPa}$ to $10 \mathrm{MPa}$ in IFSS data for bamboo fibre with nearly the same embedded length of $200 \mathrm{~mm}$ due to surface morphology.

[Insert Figure 4]

Table 1. Average value of embedded length, droplet area and fibre diameter for the different samples

\begin{tabular}{|c|c|c|c|}
\hline Sample & Embedded length( $\mu \mathrm{m})$ & $\begin{array}{l}\text { Droplet area( } \\
\left.\mu^{2}\right)\end{array}$ & Fibre diameter $(\mu \mathrm{m})$ \\
\hline Braiding yarn & $980 \pm 80$ & $710000 \pm 110000$ & $10 \pm 3$ \\
\hline $\begin{array}{l}\text { Conventional } \\
\text { optical fibre }\end{array}$ & $1410 \pm 140$ & $1080000 \pm 200000$ & $150 \pm 4$ \\
\hline $\begin{array}{l}\text { Micro-braided } \\
\text { optical fibre }\end{array}$ & $2240 \pm 240$ & $2190000 \pm 400000$ & $450 \pm 64$ \\
\hline
\end{tabular}

To perform the micro-bond test, an Instron 1122 mechanical testing machine with two movable knife edges controlled by micro-meter head as shown in the machine setup and schematic image in Figure 5. The load cell varied from $5 \mathrm{~N}$ to $100 \mathrm{~N}$ was used according to the sample diameter. The test was conducted at room temperature with displacement speed of $1 \mathrm{~mm} / \mathrm{min}$. Constant distance between the knife edge and resin droplet was maintained. During the test, force and displacement were recorded. From each curve, the de-bonding peak force $\left(\mathrm{F}_{\mathrm{D}}\right)$ was recorded. Interfacial shear strength (IFSS) between the fibres and epoxy resin was calculated using Equation (4), where $\mathrm{D}$ is the fibre diameter and $\mathrm{L}_{\mathrm{e}}$ is the embedded length.

$$
I F S S=\frac{F_{D}}{D \pi L_{e}}
$$

[Insert Figure 5]

Tensile Test

Tensile test at room temperature was conducted by closely following (ASTMD2256/D2256M, 2015). Tensile test was carried out on micro-braided optical fibre and conventional optical fibre to determine the Young's modulus, ultimate tensile strength 


\section{Three-point bend test with embedded Optical and Micro-braided optical fibres}

Three point bend test was conducted in order to determine the mechanical effect of embedding micro-braided optical fibre and conventional optical fibre on composite structures. Composite materials was manufactured using E-glass fibre Twill 2x2 woven preform (876 gsm) supplied by Sigmatex (UK) Ltd. The resin was Epoxy based: Araldite LY564 supplied by Huntsman and hardener is Aradur 2954 supplied by Mouldlife. Four layers of the woven fabric cut at $90^{\circ}$ along the axis were stacked together.

The woven fabric laminate were produced using vacuum bag assisted resin transfer infusion (VARTM). The infused preform was then cured at $80^{\circ} \mathrm{C}$ for 2 hours after 1 hour ramp time followed by 8 hours at $140^{\circ} \mathrm{C}$, after a ramp up time of 1 hour. The fibre volume fraction (measured by matrix burn of test) for laminate with conventional optical fibre was determined as $52 \pm 1 \%$, whilst the fibre volume fraction for laminate with micro-braided optical fibre was found to be $50 \pm 1 \%$.

The micro-braided optical fibre (MBOF) and conventional optical fibre (OF) were embedded between the $1^{\text {st }}$ and the $2^{\text {nd }}$ layer as described in Figure $7 \mathrm{a}$. The conventional optical fibre (OF) and micro-braided optical fibre (MBOF) were embedded just below the first layer of the preform as in a three point bend test, maximum strains are experienced into the composites.

\section{[Insert Figure 7]}

Three point bend test were conducted on the Instron 5969B11590 machine with a load cell of $50 \mathrm{kN}$. The cross-head displacement used was $2 \mathrm{~mm} / \mathrm{min}$. Specimen dimension were as follow: span length $96 \mathrm{~mm}$, width $15 \mathrm{~mm}$ and thickness $3 \mathrm{~mm}$. The setup is shown in Figure $7 \mathrm{~b}$. The dimension and all the procedures for three point bending test were in accordance with (ASTMD7264/D7264M, 2015). Three different samples were prepared; (1) with no embedded optical fibre, (2) with embedded optical fibre and (3) with embedded microbraided optical fibre.

Cross-sectional micrograph of composite panel prepared for three point bending test are shown in Figure 8 (a \& b). The presence of micro-braided and conventional optical fibre resulted in the creation of space through distortion of the fibre surrounding the micro-braided and conventional optical fibre. However, the space was filled with resin and no void formation was observed in both cases. 


\section{[Insert Figure 8]}

\section{Results and discussion}

\section{Characterisation of Micro-braided optical fibre}

The scanning electron micrograph (SEM) of micro-braided optical fibre is shown in Figure 9. Presence of filamentation mentioned in the earlier is also identified. This image was analysed using Image J (Schneider et al., 2012) to determine the braid parameters such as: the braid angles, the diameter, the percentage covered and density which is reported in Table 2 . The braid angle and braid diameter were both determined by taking several measurements at different points (10 points) along the micro-braid. Due to the nature of interlacement of the fibres, crests and troughs were created resulting in one high and one low braid diameter values. Both values were used to determine the diameter of the braid. The braid coverage around the circumference of the core is quantified using Equation 5.

$$
C F=1-\left(1-\frac{W_{y} N_{c}}{4 \pi R \cos \theta}\right)^{2}
$$

Where $\mathrm{R}$ is the radius of the core/mandrel being covered (optical fibre), $\theta$ is the braid angle, $\mathrm{N}_{\mathrm{c}}$ is the number of yarn carriers and $\mathrm{W}_{\mathrm{y}}$ is the width of the yarn (Potluri et al., 2003).

\section{[Insert Figure 9]}

The density was determined in accordance to (ASTMD1577-07, 2012). Braid crimp is the waviness or undulation of a tow as a result of interlacement between tows. Crimp angle was determined by measuring the waviness of the braiding yarn using ImageJ. The crimp angle was found to be $3.92 \pm 0.02$, and the crimp ratio $\sim 0.0032$. Crimp ratio $(\mathrm{C})$ is the ratio of the difference of non-crimped length $L_{n c}$ and crimped length $L_{c}$ of a fibre to the $L_{n c}$ as shown in Equation 6;

$C=\frac{L_{n c}-L_{c}}{L_{n c}}$

Table 2. Braid angle, diameter and coverage of micro-braided optical fibre (MBOF)

\begin{tabular}{|l|l|l|l|l|}
\hline MBOF & Braid angle( $\mathbf{(}^{\mathbf{~}}$ & Diameter $(\boldsymbol{\mu m})$ & Coverage (\%) & Density $\mathbf{( g / \mathbf { c m } ^ { 3 } )}$ \\
\hline 1 & $16.9 \pm 1.2$ & $423 \pm 61.4$ & $98.4 \pm 0.19$ & $2.214 \pm 0.07$ \\
\hline 2 & $17.3 \pm 1.7$ & $382 \pm 53.7$ & $98.3 \pm 0.27$ & $1.956 \pm 0.06$ \\
\hline 3 & $16.0 \pm 1.5$ & $407 \pm 54.3$ & $98.5 \pm 0.21$ & $2.286 \pm 0.08$ \\
\hline 4 & $16.9 \pm 0.9$ & $372 \pm 52$ & $98.3 \pm 0.14$ & $2.304 \pm 0.03$ \\
\hline
\end{tabular}


In order to determine the fibre volume fraction (FVF) of the micro-braided optical fibre, Equation 7 was used to determine the percentage of the sleeve in the micro-braiding (Potluri et al., 2003).

$F V F_{s}=\frac{N_{c}(1+C) T}{2 \pi R \rho t_{c} \cos \theta} 10^{-6}$

Where $\mathrm{T}$ is the linear density of the yarn $\mathrm{g} / \mathrm{km}, \rho$ is the density of the MBOF; $\mathrm{N}_{\mathrm{C}}$ is the number of yarn carriers, $C$ is the crimp ratio due to interlacement, $t_{c}$ is the thickness of MBOF, $R$ is the effective mandrel radius and $\theta$ is the braid angle. The calculated fibre volume fraction of sleeve was 0.41 .

The fibre volume fraction of the micro-braiding and the optical fibre was calculated using Equations 8-9; where $A_{B}$ is the area of braid, $T_{a}$ is the total area, $A_{O F}$ is area of optical fibre and $\mathrm{A}_{\mathrm{AB}}$ is actual area occupied by braid. Obtaining measurement from cross-sectional image of composite panel embedded with micro-braided optical fibre as shown in Figure $8 \mathrm{~b}$ in the previous section.

$$
A_{A B}=F V F_{s} \times A_{B}
$$

$F V F_{M B}=\frac{A_{n}}{T_{a}}, F V F_{O F}=\frac{A_{O F}}{T_{a}}$

Effect of Micro-braiding on FBG sensor

The effect of micro-braiding on the FBG sensor was monitored by measuring the change in wavelength before and after micro-braiding. A typical reflection spectrum of MBOF and OF is shown in Figure 10. The average strain acquired as a result of micro-braiding the optical fibre was $(\varepsilon=-0.072 \pm 0.008 \%)$. The negative value of strain was due to the compressive effect of the braiding yarns on the FBG. Moreover, the peak change as shown in Figure 10 is negligible which indicates that the micro-braiding of the optical fibre does not cause any damage on the sensor. It is also observed that there was noise in the response spectra of the $\mathrm{OF}$ and MBOF. This could be due to effect of the light source or the photodiode (coupler) (Hafizi and Epaarachchi, 2015). But because we are interested in the peak, the noise will not disturb the sensitivity of the optical fibre.

\section{[Insert Figure 10]}

\section{Tensile test}

Tensile test results of conventional optical fibre (OF) and micro-braided optical fibre (MBOF) are presented to demonstrate the effect of micro-braiding on the enhancement of its 
mechanical properties. Figure $11(\mathrm{a} \& \mathrm{~b})$ show the stress-strain curve for both $\mathrm{OF}$ and MBOF. Figure 11a shows the stress vs strain curve for conventional optical fibre, $20-25 \%$ deviation in stress value was observed in the stress value, while 11-32\% deviation was observed in the strain value. This could be due to the effect of handling (holding, gripping or touching) on the intrinsic property of the optical fibre. Deviation in stress and strain of conventional optical fibres has also been reported by Antunes (Antunes et al., 2012). The slight difference in the stress values observed in Figure $11 \mathrm{~b}$ for MBOF might be due to variation in the braid diameter and the braid angle. The increase in stress value observed in the MBOF is due to the presence of glass fibre tows which have a high strength $(1663 \pm 230$ MPa). However, as a result of braid angle (Atas et al., 2017; Gautam et al., 2017; Gautam et al., 2016; Gautam et al.; Pavlopoulou et al., 2017) and due the presence of crimp (due to interalacement) the overall contribution of glass tows towards the tensile strength gets reduced.

Figure 11c shows the zoomed image of the stress vs strain curve for the MBOF; it can be seen in that the sample failed at the gauge length in between the grating, this can be due to the stress concentration around the grating. Some of the samples showed an obvious failure of the optical fibre in the micro-braiding. This result shows why optical fibres often gets damaged when incorporated between or along the interlaced tows in a woven or braided fabric, or when used as axial tows in a triaxial braid, or when knitted into fabric. With the help of a layer of micro-braid, this problem can be eliminated, as the braid layer provides a protective layer to the optical fibre preventing it from getting damaged.

\section{[Insert Figure 11]}

The strain at failure for MBOF is between 1.45-1.525\%. However, the S-glass yarn continued to carry the load up to final failure at about $2.5 \%$ strain, because the strain at failure of Sglass is between 1.2-3.1\% (PriceEngineering). There was about $85 \%$ increase in strain limit of the MBOF compared to the OF. The strain at failure reading of the FBG interrogator were calculated using wavelength shift and then plotted against time as shown in Figure 12(a \& b).

\section{[Insert Figure 12]}

The measured strain by the FBG interrogator and the tensile machine for both OF and MBOF are plotted together to show accuracy in the measurement as shown in Figure 13. From the graph, it can be seen that similar strain value was recorded by the FBG interrogator and the tensile machine for the $\mathrm{OF}$ and $\mathrm{MBOF}$.

\section{[Insert Figure 13]}

The micro-braiding of conventional optical fibre has shown so many advantages such as improvement of handling and increase in strain at failure. Figure 14 shows the average value of the Young's modulus, ultimate tensile strength (UTS) and strain at UTS for OF and 
Where $\mathrm{E}_{\mathrm{MBOF}}, \mathrm{E}_{\mathrm{BY}}$ and $\mathrm{E}_{\mathrm{OF}}$ are the Young's modulus of the micro-braided optical fibre, braiding yarn and the optical fibre; and $\mathrm{FV}_{\mathrm{MB}}$ and $\mathrm{FV}_{\mathrm{OF}}$ are the volume fraction of the microbraiding and the optical fibre respectively. Derived experimental Young's modulus was $39 \pm$ 3.99 GPa while theoretical Young's modulus was $34 \pm 3.10 \mathrm{GPa}$.

\section{[Insert Figure 14]}

\section{Micro-bond test}

The micro-bond test for different fibres (S-glass yarn, conventional optical fibre and microbraided optical fibre) is discussed. Typical stress-strain curve for the samples is shown in Figure 15. From Figure 15a, no noticeable friction was observed during the pull. However, breakage of fibre occurred between the droplet and the fibre due to high embedded length i.e. $\mathrm{L}_{\mathrm{e}}=\mathrm{L}_{\mathrm{c}}$ (critical length). This is also the reason for the high value of stress observed. Favre also reported the existence of good adhesion for similar load-displacement curve that showed a sharp breakage when $\Delta \mathrm{L}>\mathrm{L}_{\mathrm{e}}$. It is assumed that the stored elastic energy is enough to pull the fibre without any noticeable friction (Favre and Merienne, 1981). Figure 15b shows typical stress vs strain curve for conventional optical fibre. De-bonding of droplet starts as the pull force increase up to the peak, after which sudden decrease of about $55 \%$ was observed. After the peak force, it showed fluctuation until the resin droplet was pulled out of the optical fibre completely. This phenomenon indicates friction force exist between the droplet and the fibre during the pull as observed by other researchers (Desarmot and Favre, 1991; Miller et al., 1991). A typical curve for micro-braided optical fibre is given in Figure $15 \mathrm{c}$, initial deviation in stress was observed due to the breakage of resin that wet the MBOF before it increased up to the peak value. It is observed that the stress value for the MBOF is low, due to the removal of part of the resin droplet leaving behind some resin residue on the fibre as shown in Figure 16a. It has also been reported that fibre wetting causes a meniscus region to form around the fibre (Mader and Freitag, 1990). Because the resin coating is thinner in the meniscus it causes rupture prior to de-bonding. Presence of residual resin indicates cohesive matrix failure which affects the interfacial shear strength of the sample (Yang and Thomason, 2010). 


\section{[Insert Figure 15]}

[Insert Figure 16]

A plot of stress against embedded area is shown in Figure 17 for the data obtained from the $\mathrm{BY}, \mathrm{OF}$ and MBOF by micro-bond test. It is observed that stress decreases as the embedded area increases. $\mathrm{R}^{2}$ values for the MBOF and the OF shows that robustness of the $\mathrm{OF}$ increased as a result of micro-braiding. IFSS was calculated using Equation 3, the value for braiding yarn (BY) was $5.28 \pm 0.61 \mathrm{MPa}$ which agrees well with the interfacial shear strength (IFSS) range published in literature (3-6 MPa) (Hoecker and Karger-kocsis, 1993; Mader and Freitag, 1990; Thomason and Schoolenberg, 1994). The IFSS value for conventional optical fibre and micro-braided optical fibre are 16.5 $\pm 1.86 \mathrm{MPa}$ and $11.5 \pm 0.46 \mathrm{MPa}$ respectively. The reason for the low IFSS in MBOF could be due to the cohesive matrix failure caused by the surface morphology of MBOF as a result of undulation of fibre due to crimp. While the increase in IFSS of OF could be attributed to the presence of adhesive interfacial failure (fibre with cleaner surface) as shown in the de-bonded fibre surface in Figure 16b.

\section{[Insert Figure 17]}

\section{Three-point bending test}

A major objective of this test is to determine the effect of embedded optical fibre (both conventional and micro-braided) on the integrity of the composite panel. The manufactured composite was subjected to three point bend test with the embedded layer in the compressive direction, this will make it possible to study the effect of the embedded OF and MBOF on the structural integrity of the composite panel. The primary purpose of this study was to determine if embedding OF and MBOF would decrease the mechanical performance of the composite panel. The main reason to use micro-braided optical fibre is to protect the brittle optical fibre during handling and automated manufacture of composite materials (i.e. braiding, winding, etc.)

The typical stress-strain curve is shown in Figure 18 (a \& b). The linear behaviour is observed up to initial breakage of the first plies. This is due to the elastic deformation of the composite panel. After the flexural stress reached the peak in the first region, drop in peak stress was observed in the composite panel in the second region and this drop was due to fibre cracking and delamination. $21 \%$ drop in peak stress value was observed in the composite panel with no optical fibre and $20-22 \%$ was observed in the composite panel with optical fibre and micro-braided optical fibre respectively. All the specimens could still withstand load application but never reached the peak till final failure. From Figure 18b, slight slippage was however noticed with laminate embedded with MBOF at about $265 \mathrm{MPa}$ which indicates early delamination but still carried the load up to $280 \mathrm{MPa}$. The early delamination could be due to the increased diameter of the micro-braided optical fibre; however, this did not pose any major challenge on the composite panel. The early 
delamination observed was about $5 \%$ less than the peak value of the composite panel with no optical fibre and $3.8 \%$ less than the composite panel with optical fibre. This difference is not significant enough to affect the integrity of the composite panel. This also confirms that the localised distortion observed in the optical image due to embedding MBOF and OF did not cause deterioration in the mechanical property. This type of behaviour was also observed by (Hamouda et al., 2015). The diameter of the conventional optical fibre was $150 \mu \mathrm{m} \pm 4$ while that of the micro-braided optical fibre is $450 \mu \mathrm{m} \pm 64$. This difference in the diameter of the OF and MBOF did not cause any significant change in the mechanical performance of the composite panel from the experimental test results.

\section{[Insert Figure 18]}

The optical micrograph of damaged composite under three point load for both types of optical fibres (OF and MBOF) shows inter-layer delamination due to compressive loads (Figure 19).

\section{[Insert Figure 19]}

The average value of flexural test result is presented in Figure 20. It is observed that there is $3.2 \%$ difference in UFS of micro-braided optical fibre compared to the composite panel with no optical fibre. The percentage difference is not high enough to cause any significant effect in composite structures. The strain at UTS of the composite panel with micro-braided optical fibre showed 5\% increase compared to the panel with conventional optical fibre, this could be due to the braiding yarn acting as another layer to protect the optical fibre; thereby allowing the optical fibre to experience more elongation before failure. However, the flexural modulus of the samples is between the range of 14-14.4 GPa, which indicates that embedding of micro-braided optical fibre has no significant effect on the modulus of elasticity of the composite panel. It can be inferred from this result that micro-braided optical fibre would have little or no influence on the integrity of the composite structure.

[Insert Figure 20]

\section{Conclusion}

In the study conducted in this paper, the technique of optimising (improved handing and mechanical properties) the optical fibres through micro-braiding was presented. This study showed that the developed technique does not result in affecting the sensitivity or causing any damage to the optical fibre (that are micro-braided). The tensile response of both conventional optical fibre and micro-braided optical fibre were investigated. Micro-braided optical fibre (MBOF) showed $85 \%$ increase in strain at failure compared to conventional optical fibre. This was due to the cushion effect the micro-braiding has on the optical fibre which increased the elongation of the optical fibre. However, decrease in the Young's modulus observed could be attributed to the effect of crimp causing undulation of braid yarn.

Micro-bond test shows the improvement in the robustness of micro-braided optical fibre (MBOF) based on the higher $\mathrm{R}^{2}$ value observed compare to OF. However, IFSS of conventional optical fibre was higher than micro-braided optical fibre. This was due to 
cohesive matrix failure observed in the MBOF due to its surface morphology. Suggestion for future work will be to do some surface treatment on the MBOF. Three-point bend test of composite laminate with no optical fibre and with micro-braided optical fibre and conventional optical fibre shows that the integrity of the composite laminate is not affected by the presence of the micro-braided optical fibre. In near future, the use of MBOF can be used as alternative to conventional optical fibre to improve SHM.

\section{Declaration of conflicting interests}

The authors declare no conflict of interest regarding the research, authorship and publication of article.

\section{Funding}

The authors will like to appreciate Schlumberger Foundation for funding, which made this research possible. The authors will also like to thank the staff of University of Manchester, who helped in manufacturing and running of test.

\section{ORCID iD}

Olubukola Rufai iDorcid.org/0000-0001-9950-3932

\section{References}

Agy. 493 S-2 Glass Yarn. Available at: http://pdf.directindustry.com/pdf/agy/493-s-2-glassyarn/50640-559265.html.

Antunes P, Domingues F, Granada M, et al. (2012) Mechanical Properties of Optical Fibers. 1-15.

ASTMD1577-07. (2012) Standard test methods for linear density of textile fibers.

ASTMD2256/D2256M. (2015) Standard Test Method for Tensile Properties of Yarns by the SingleStrand Method. D2256/D2256M.

ASTMD7264/D7264M. (2015) Standard Test Method for Flexural Properties of Polymer Matrix Composite Materials.

Atas A, Gautam M, Soutis C, et al. (2017) Bolted Joints in Three Axially Braided Carbon Fibre/Epoxy Textile Composites with Moulded-in and Drilled Fastener Holes. Applied Composite Materials 24: 449-460.

Brunnschweiler D. (1953) Braids and Braiding. Journal of the Textile Institute Proceedings 44:9: 666686.

Carroll BJ. (1976) The Accurate Measurement of Contact Angle, Phase Contact Areas, Drop Volume, and Laplace Excess Pressure in Drop-on-Fiber Systems. Journal of Colloid and Interface Science 56: 488-495.

Chandarana N, Sanchez DMSC and Gresil M. (2017) Early Damage Detection in Composites during Fabrication and Mechanical Testing. Materials 10: 1-16.

Costa L, Gresil M and Frazão O. (2016) Simultaneous measurement of physical parameters using FBGs embedded in unidirectional and bidirectional composite materials. SMART MATERIALS AND STRUCTURES 25: 1-8.

Del Rosso S, lannucci L and Curtis PT. (2015) Experimental investigation of the mechanical properties of dry microbraids and microbraid reinforced polymer composites. Composite Structures 125: 509-519. 
Desarmot G and Favre JP. (1991) Advances in Pull-Out Testing and Data Analysis. Composites Science and Technology 42: 151-187.

Favre JP and Merienne MC. (1981) Characterization of fibre/resin bonding in composites using a pullout test. International Journal of Adhesion and Adhesives: 311-316.

Gautam M, Katnam KB, Potluri P, et al. (2017) Hybrid composite tensile armour wires in flexible risers: A multi-scale model. Composite Structures 162: 13-27.

Gautam M, Potluri P, Katnam KB, et al. (2016) Hybrid composite wires for tensile armours in flexible risers: Manufacturing and mechanical characterisation. Composite Structures 150: 73-83.

Gautam M, Potluri P, Ogin S, et al. Necking Behaviour of Flattened Tubular Braided Composites. Copenhagen, 1-11.

Gholami M, Ahmadi MS, Tavanaie MA, et al. (2017) Effect of oxygen plasma treatment on tensile strength of date palm fibers and their interfacial adhesion with epoxy matrix. Science and Engineering of Composite Materials: 1-9.

Guemes A, Fernandez-Lopez A and Soller B. (2010) Optical Fiber Distributed Sensing - Physical Principles and Applications. Structural Health Monitoring 9: 233-245.

Hafizi ZM and Epaarachchi J. (2015) Dynamic Response and Signal to Noise Ratio Investigation of NIR-FBG Dynamic Sensing System for Monitoring Thin- walled Composite Plate. 3rd International Conference of Mechanical Engineering Research (ICMER 2015). Kuantan, Malaysia: IOP Publishing, 1-10.

Hamouda T, Seyam A-F and Peters K. (2015) Evaluation of the Integrity of 3D Orthogonal Woven Composites with Embedded Polymer Optical Fibers. Composites Part B 78: 79-85.

Hamouda TM, Seyam AM and Saad MM. (2010) Prediction of Failure of 3D Woven Composite Structures using Embedded Fiber Optic Sensors. World Journal of Engineering 7: 103-112.

Heieck F, Hermann F, Middendorf P, et al. (2017) Influence of the cover factor of 2D biaxial and triaxial braided carbon composites on their in-plane mechanical properties. Composite Structures 163: 114-122.

Hoecker F and Karger-kocsis J. (1993) Effects of crystallinity and supermolecular formations on the interfacial shear strength and adhesion in GF/PP composites. 707-714.

Hufenbach W, Gude M, Czulak A, et al. (2014) Development and implementation of an automatic integration system for fibre optic sensors in braiding process with the objective of online monitoring of composites. SPIE Optics + Photonics 2014. San diego, USA, 1-14.

Huntsman. (2010) Advanced Materials Araldite ${ }^{\circledR}$ LY 1564 SP / Aradur ${ }^{\circledR} 2954$. Advanced Materials: 1-4.

ISO BE. (2062:1995) Textiles. Yarns from packages. Determination of single-end breaking force and elongation at break. 3-7.

Kreuzer M. Strain Measurement with Fiber Bragg Grating Sensors. Darmstardt, Germany, 1-27.

Lee CS, Hwang W, Park HC, et al. (1999) Failure of carbon/epoxy composite tubes under combined axial and torsional loading 1. Experimental results and prediction of biaxial strength by the use of neural networks. Composites Science and Technology 59: 1779-1788.

M Y. (2008) Loading Rate Sensitivity of High Strength Fibers and Fiber/Matrix Interfaces. Journal of REINFORCED PLASTICS AND COMPOSITES 28: 1869-1880.

Mader E and Freitag KH. (1990) Interface properties and their influence on short fibre composites. Composites 21: 397-402.

Miller B, Gaur U and Hirt DE. (1991) Measurement and Mechanical Aspects of the Microbond PullOut Technique for Obtaining Fiber/Resin Interfacial Shear Strength. Composites Science and Technology 42: 207-219.

Milwich M, Dauner M and Planck H. (1995) Optimisation of Process Conditions and Braid Structure in Braiding Reinforcing Products Using High-Performance Fibres. Band- Und Flechtindustrie 2: 44-55.

Nawaz S, Potluri P, Gautam M, et al. (2013) Study of Braid Topology and Effect of Braid Pattern on Composite Properties. 19th International Conference on Composite Materials. Montreal, Canada, 689-695. 
Nishikawa M, Okabe T, Hemmi K, et al. (2008) Micromechanical modeling of the microbond test to quantify the interfacial properties of fiber-reinforced composites. International Journal of Solids ans Structures 45: 4098-4113.

Omeroglu S. (2006) The Effect of Braiding Parameters on the Mechanical Properties of Braided Ropes. FIBRES \& TEXTILES in Eastern Europe 14: 53-57.

Pavlopoulou S, Roy SS, Gautam M, et al. (2017) Numerical and Experimental Investigation of the Hydrostatic Performance of Fibre Reinforced Tubes. Applied Composite Materials 24: 417448.

Potluri P, Rawal A, Rivaldi M, et al. (2003) Geometrical modelling and control of a triaxial braiding machine for producing 3D preforms. Composites - Part A: Applied Science and Manufacturing 34: 481-492.

PriceEngineering. Fibre Reinforced Polymers Characteristics and Behaviors.

Rong MZ, Zhang MQ, Liu Y, et al. (2001) The effect of fiber treatment on the mechanical properties of unidirectional sisal-reinforced epoxy composites. Composites Science and Technology 61: 1437-1447.

Rufai O, Gautam M, Potluri M, et al. Optimisation of Optical Fibres for Structural Health Monitoring Through Micro-braiding. Stanford, CA.

Sanchez DM, Gresil M and Soutis C. (2015) Distributed internal strain measurement during composite manufacturing using optical fibre sensors. Composites Science and Technology 120: 49-57.

Schneider CA, Rasband WS and Eliceiri KW. (2012) NIH Image to ImageJ: 25 years of image analysis. Nature methods 9: 671-675.

Sree Shankhachur R and Potluri P. (2016) Braiding: From Cordage to Composites. 3rd Textile Research Conference (TRC). Dhaka City, Bangladesh, 1-4.

Takeda N, Okabe Y, Kuwahara J, et al. (2005a) Development of smart composite structures with small-diameter fiber Bragg grating sensors for damage detection: Quantitative evaluation of delamination length in CFRP laminates using Lamb wave sensing. Composites Science and Technology 65: 2575-2587.

Takeda S, Okabe Y and Takeda N. (2002) Delamination detection in CFRP laminates with embedded small-diameter fiber Bragg grating sensors. Composites - Part A: Applied Science and Manufacturing 33: 971-980.

Takeda S, Okabe Y, Takeda N, et al. (2005b) Delamination monitoring of laminated composites subjected to low-velocity impact using small-diameter FBG sensors. Composites Part A: 903908.

Takeda S, Okabe Y, Yamamoto T, et al. (2003) Detection of edge delamination in CFRP laminates under cyclic loading using small-diameter FBG sensors. Composites Science and Technology 63: 1885-1894.

Tate JS, Kelkar AD and Whitcomb JD. (2006) Effect of braid angle on fatigue performance of biaxial braided composites. International Journal of Fatigue 28: 1239-1247.

Thomason JL and Schoolenberg GE. (1994) An investigation of glass fibre/ polypropylene interface strength and its effect on composite properties. Composites 25: 197-203.

Tsuda H. (2006) Ultrasound and damage detection in CFRP using fiber Bragg grating sensors. Composites Science and Technology 66: 676-683.

Tsuda $\mathrm{H}$, Toyama N and Takatsubo J. (2004) Damage detection of CFRP using fiber Bragg gratings. JOURNAL OF MATERIALS SCIENCE 39: 2211-2214.

Wang $\mathrm{H}$, Tian G, Wang $\mathrm{H}$, et al. (2014) Pull-out method for direct measuring the interfacial shear strength between short plant fibers and thermoplastic polymer composites (TPC). Holzforschung 68: 17-21.

Wang H, Wang H, Li W, et al. (2013) An improved microbond test method for determination of the interfacial shear strength between carbon fibers and epoxy resin. Polymer Testing 32: 14601465. 
Xiao X, Kia HG and Gong X-J. (2011) Strength prediction of a triaxially braided composite. Composites - Part A 42: 1000-1006.

Yang $L$ and Thomason JL. (2010) Interface strength in glass fibre-polypropylene measured using the fibre pull-out and microbond methods. Composites - Part A 41: 1077-1083.

Yuan S, Huang R and Rao Y. (2004) Internal Strain Measurement in 3D Braided Composites Using Cobraided Optical Fiber Sensors. Journal of Material Science and Technology 20: 199-202. 


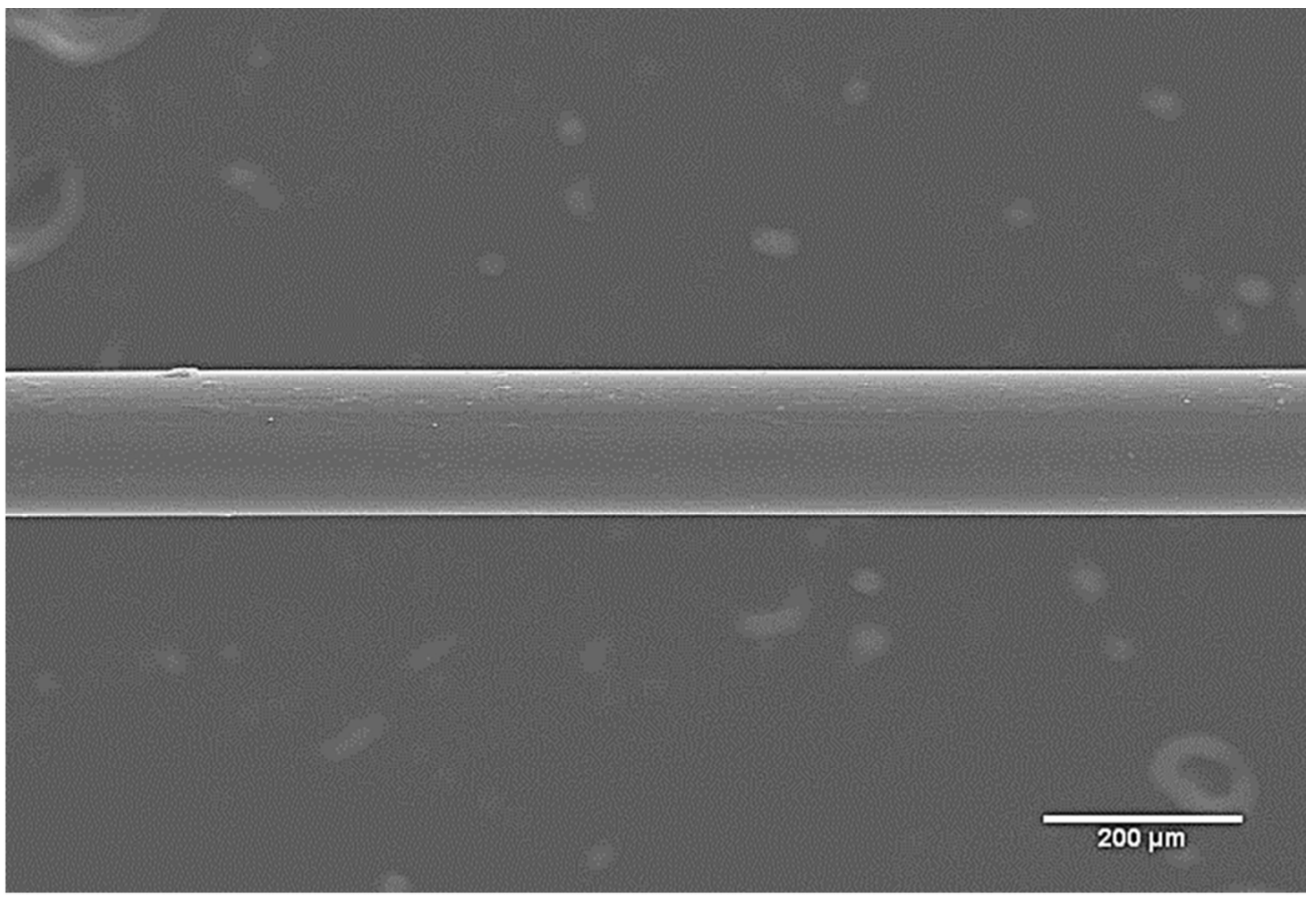

Figure 1. Scanning electron micrograph (SEM) of a conventional optical fibre (OF) sensors. $75 \times 51 \mathrm{~mm}(600 \times 600 \mathrm{DPI})$ 


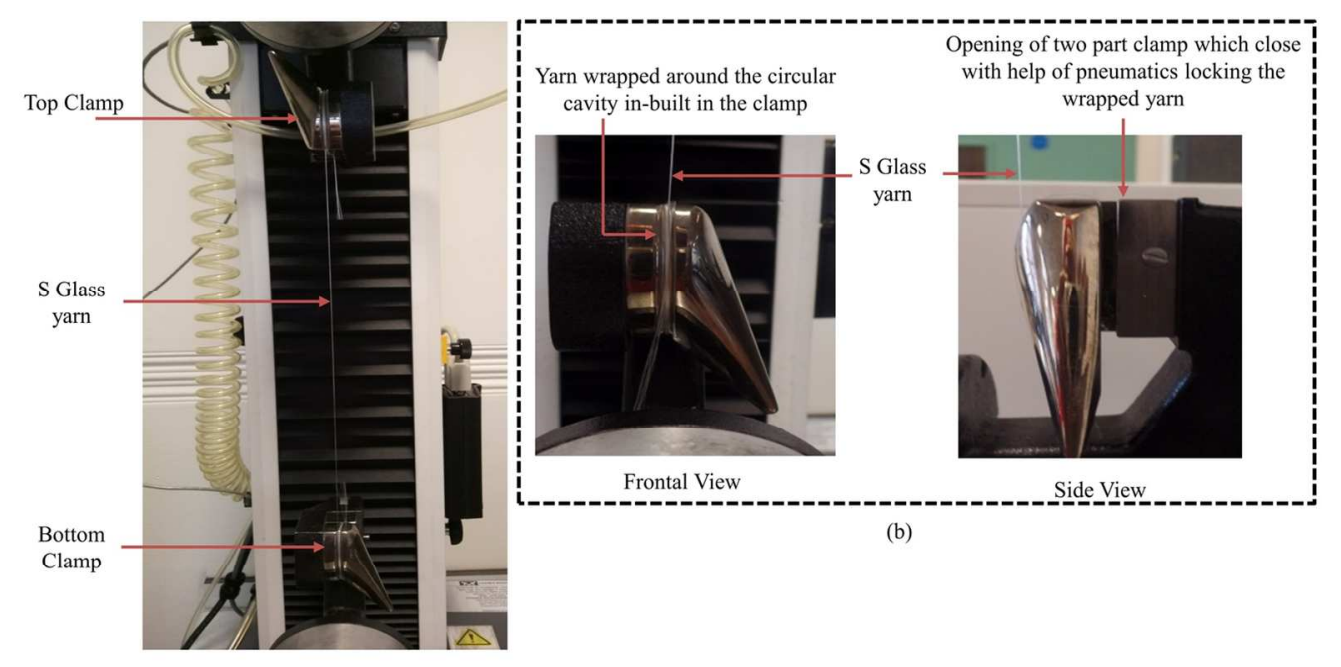

(a)

Figure 2. (a) Setup for tensile test of S-glass and (b) zoomed clamping procedure.

$129 \times 68 \mathrm{~mm}(300 \times 300 \mathrm{DPI})$ 
Bobbin mounted onto the
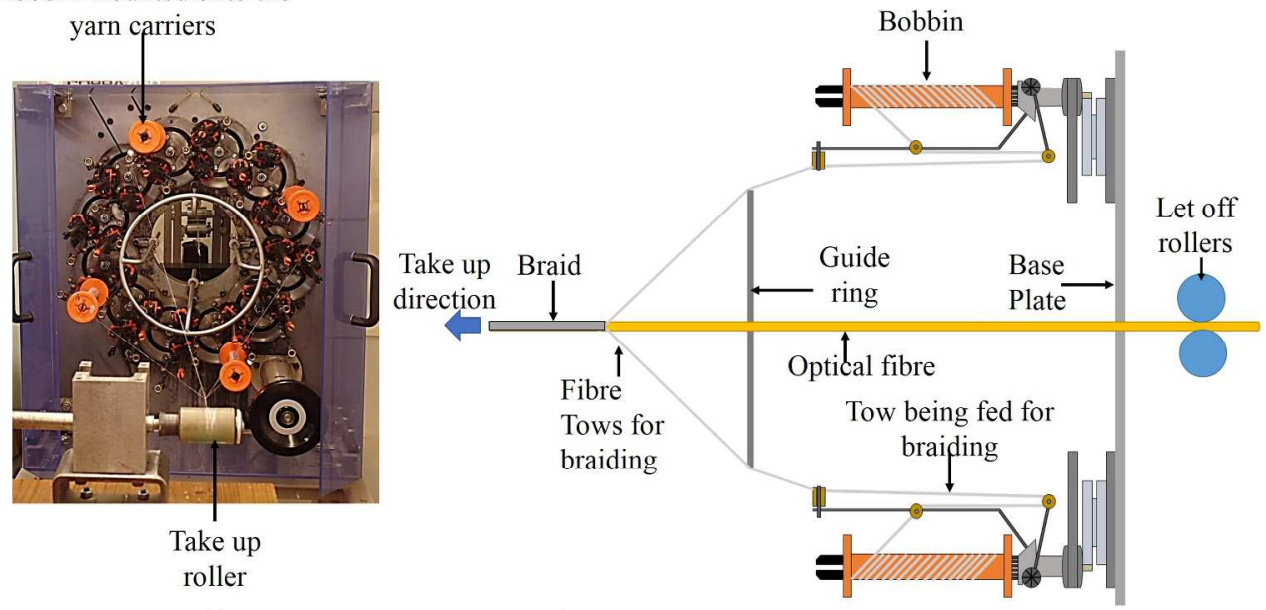

(a)

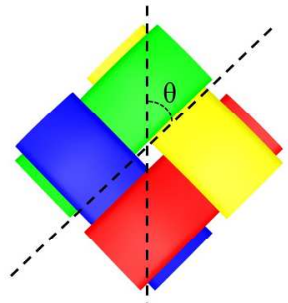

(b)

(c)

Figure 3. (a) 24 carrier braiding machine set up for micro-braiding the optical fibre, and (b) schematic image of braiding process (c) Schematics of diamond braid geometry TexGen (28), $\theta$ is the braid angle.

$441 \times 342 \mathrm{~mm}(150 \times 150 \mathrm{DPI})$ 


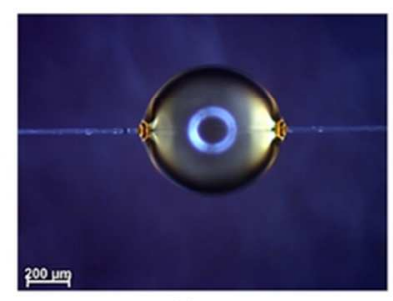

(a)

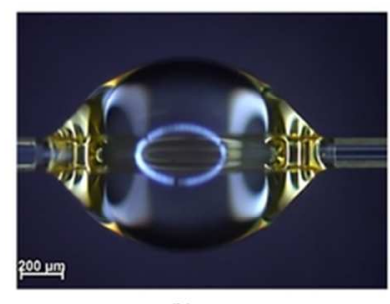

(b)

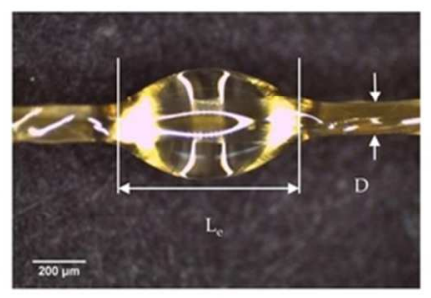

(c)

Figure 4. Optical image of resin droplet onto (a) S-glass yarn, (b) Conventional optical fibre and (c) Microbraided optical fibre.

$66 \times 18 \mathrm{~mm}(300 \times 300$ DPI $)$ 


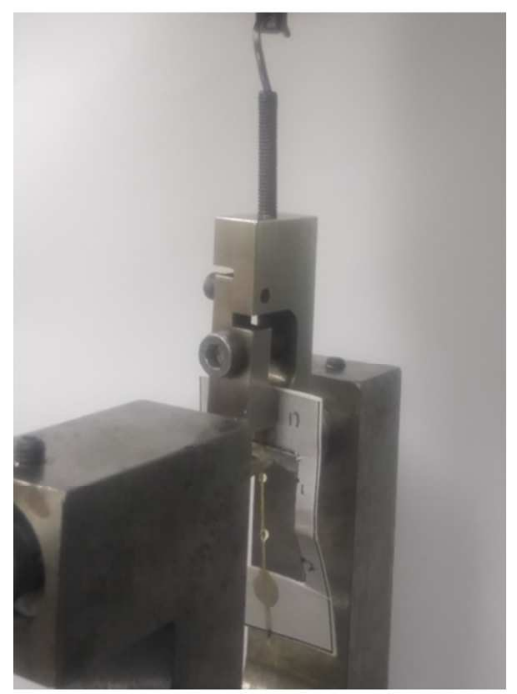

(a)

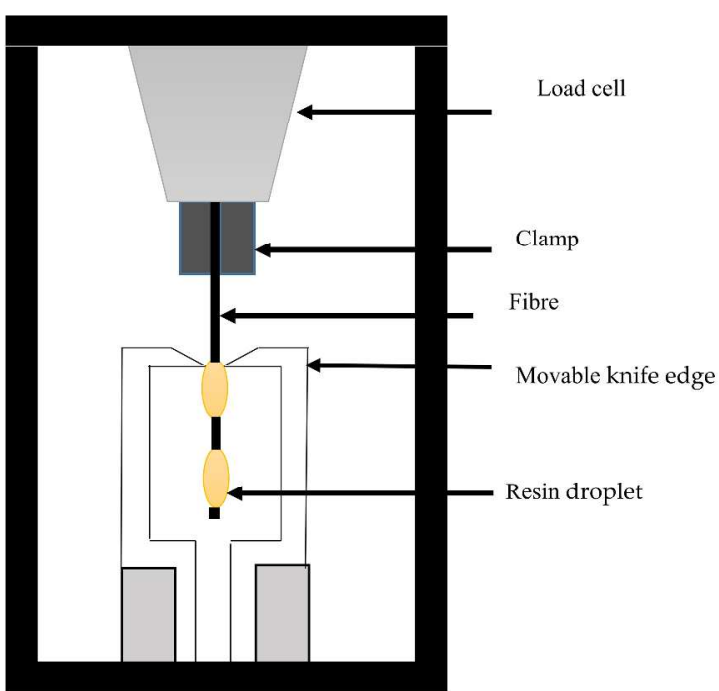

(b)

Figure 5. (a) Machine setup for micro-bond test (b) Schematic image of the micro-bond test setup. 


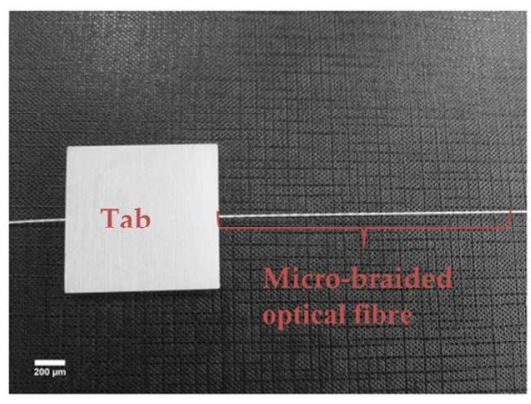

(a)

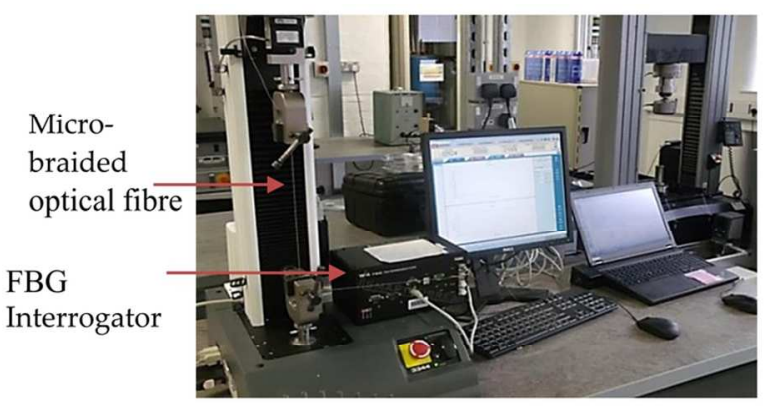

(b)

Figure 6. (a) Zoomed image of the glass tabbing of the micro-braided optical fibre (MBOF); (b) Setup for strain measurement with FBG interrogator during tensile test.

$55 \times 19 \mathrm{~mm}(600 \times 600 \mathrm{DPI})$ 


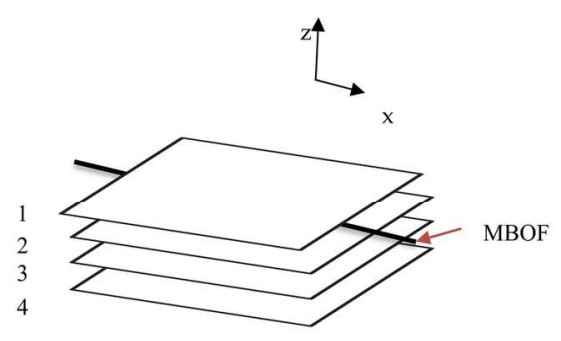

(a)

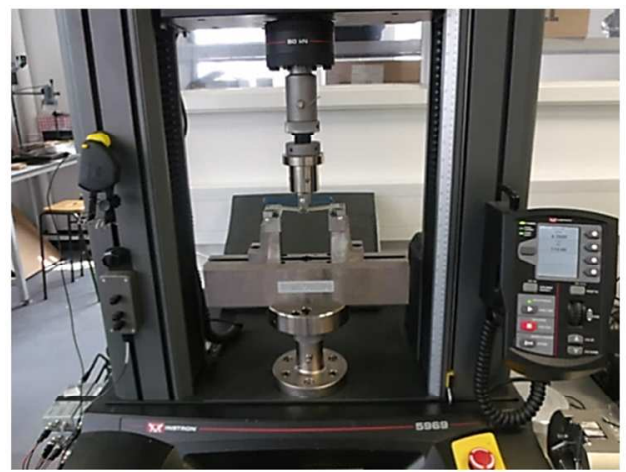

(b)

Figure 7. Layup of fabric with micro-braided optical fibre (MBOF) or conventional optical fibre (OF) embedded between 1 st and 2nd layer ( $z$ axis is through the fibre thickness and $x$ axis is along the warp direction).

$79 \times 31 \mathrm{~mm}(600 \times 600 \mathrm{DPI})$ 


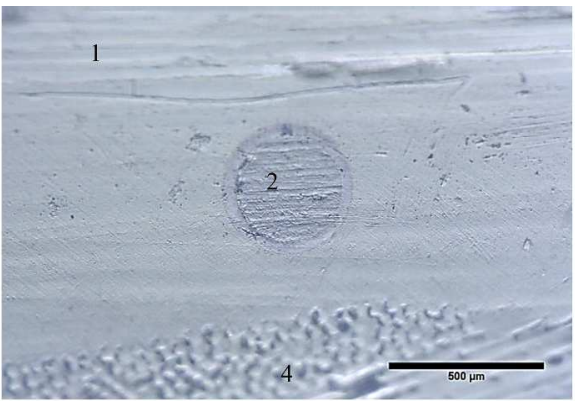

(a)

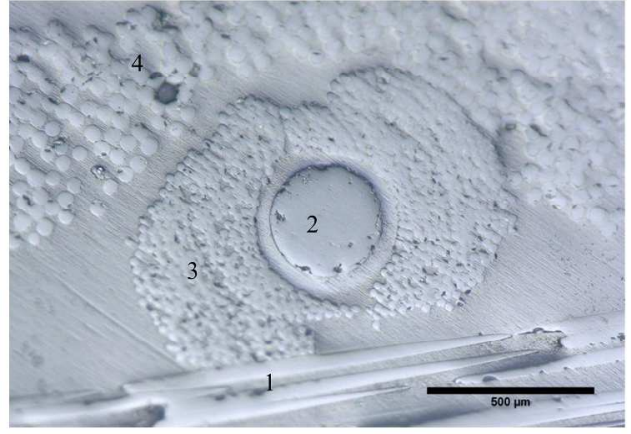

(b)

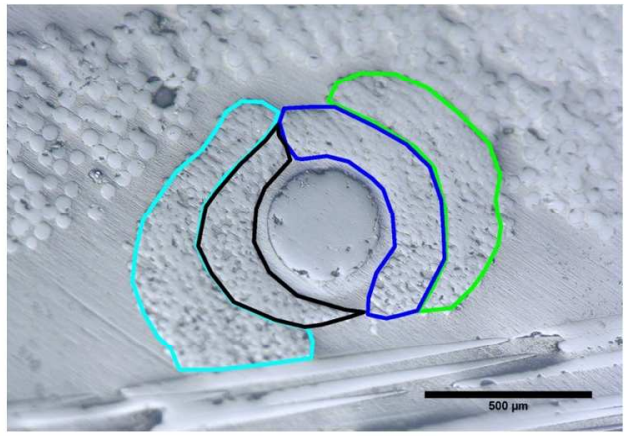

(c)

Figure 8 ( $a$ and $b$ ). Cross section of embedded of micro-braided optical fibre (MBOF) and conventional optical fibre (OF) (1) Longitudinal glass fibre, (2) OF embedded between layers of glass fibre (3) Braiding tows, (4) Transverse glass fibre. 7c shows the trace-out of the 4 braiding tows

$$
131 \times 92 \mathrm{~mm}(600 \times 600 \text { DPI })
$$




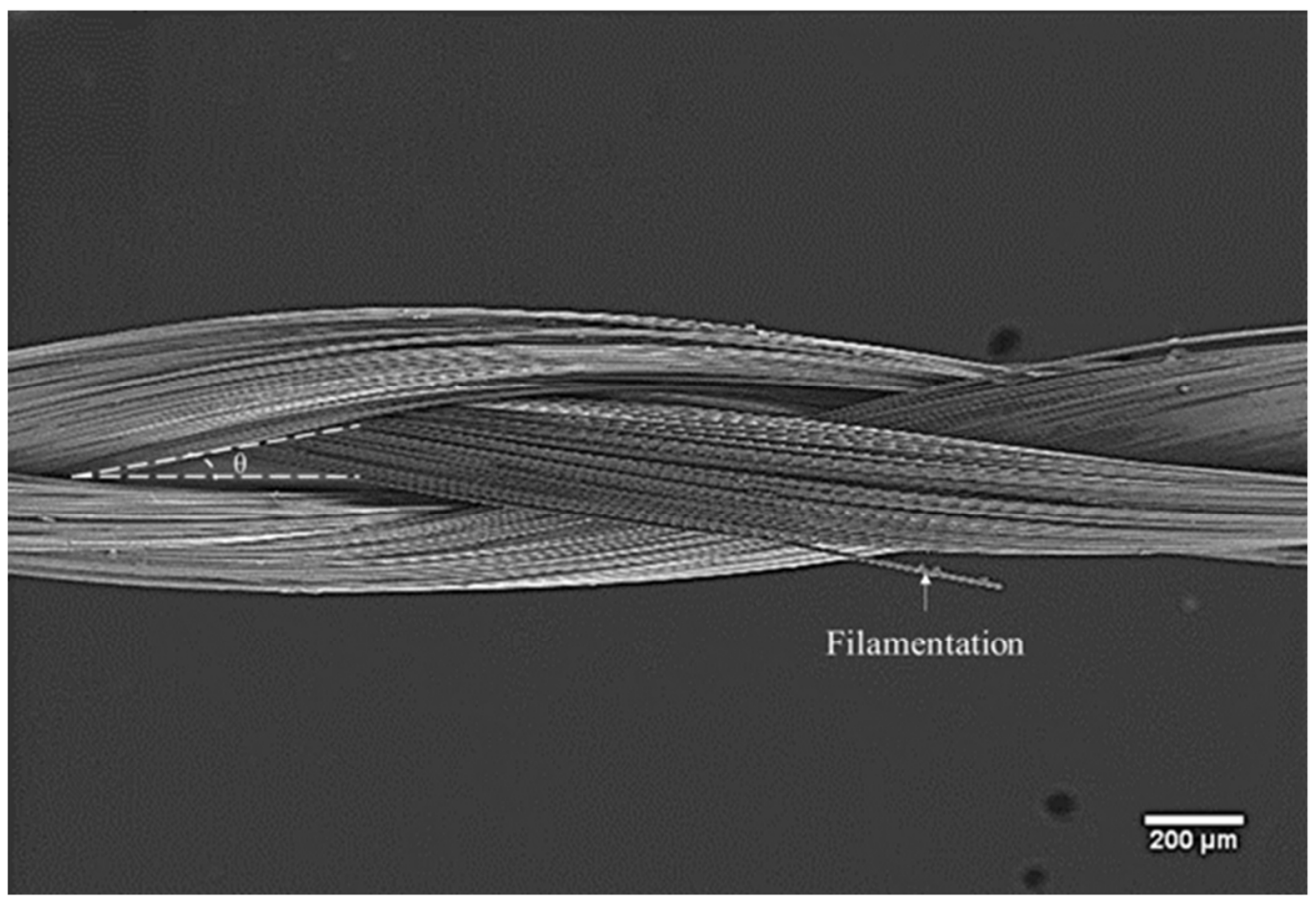

Figure 9. Scanning electron micrograph (SEM) of micro-braided optical fibre (MBOF) where $\theta$ is the braid angle.

$68 \times 46 \mathrm{~mm}(600 \times 600 \mathrm{DPI})$ 


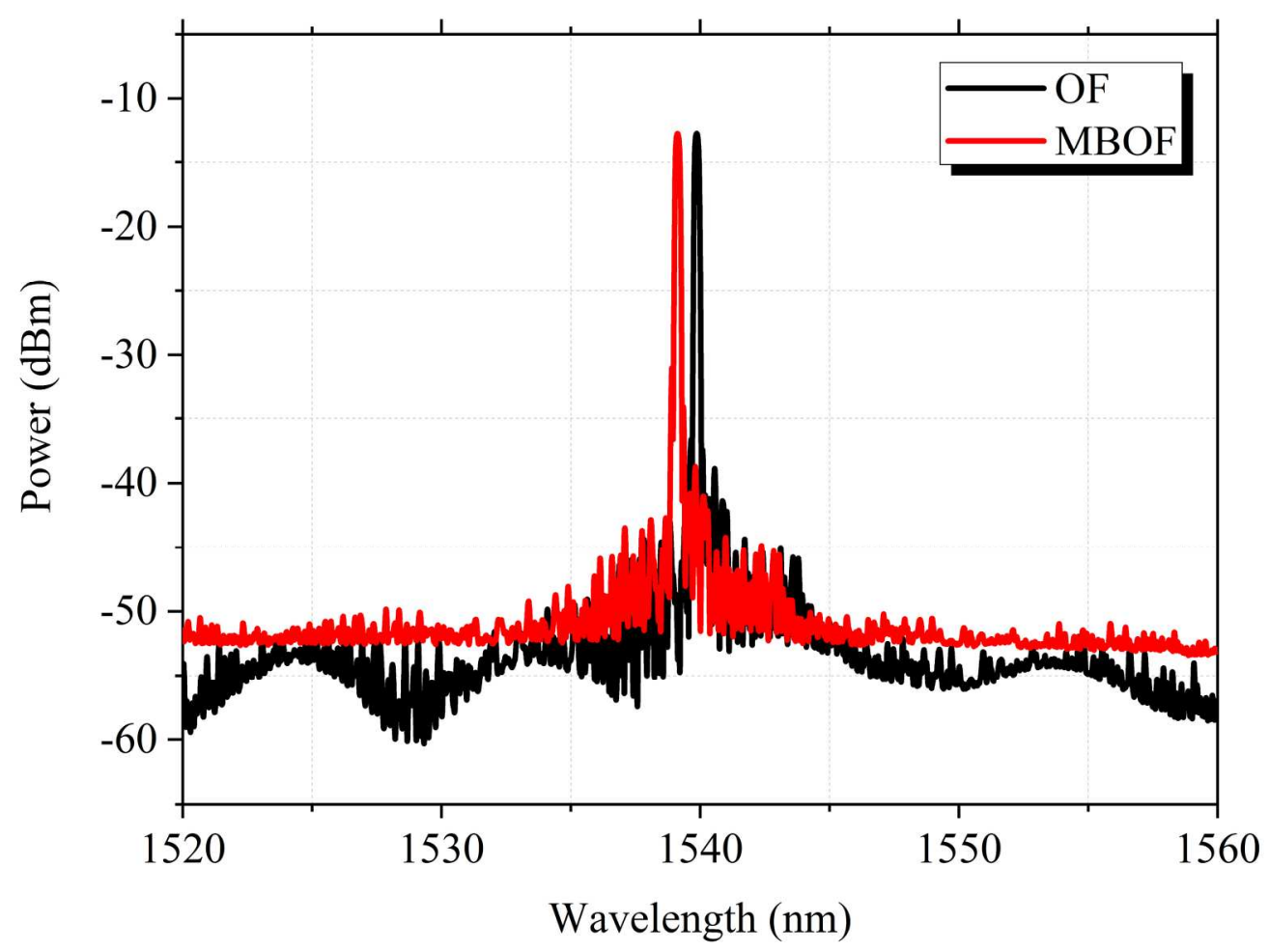

Figure 10. Typical wavelength spectra of Micro-braided optical fibre (MBOF) and Conventional optical fibre (OF).!! +

$181 \times 134 \mathrm{~mm}(300 \times 300 \mathrm{DPI})$ 


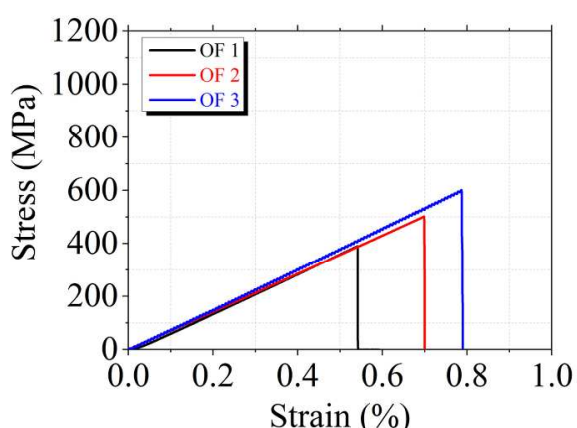

(a)
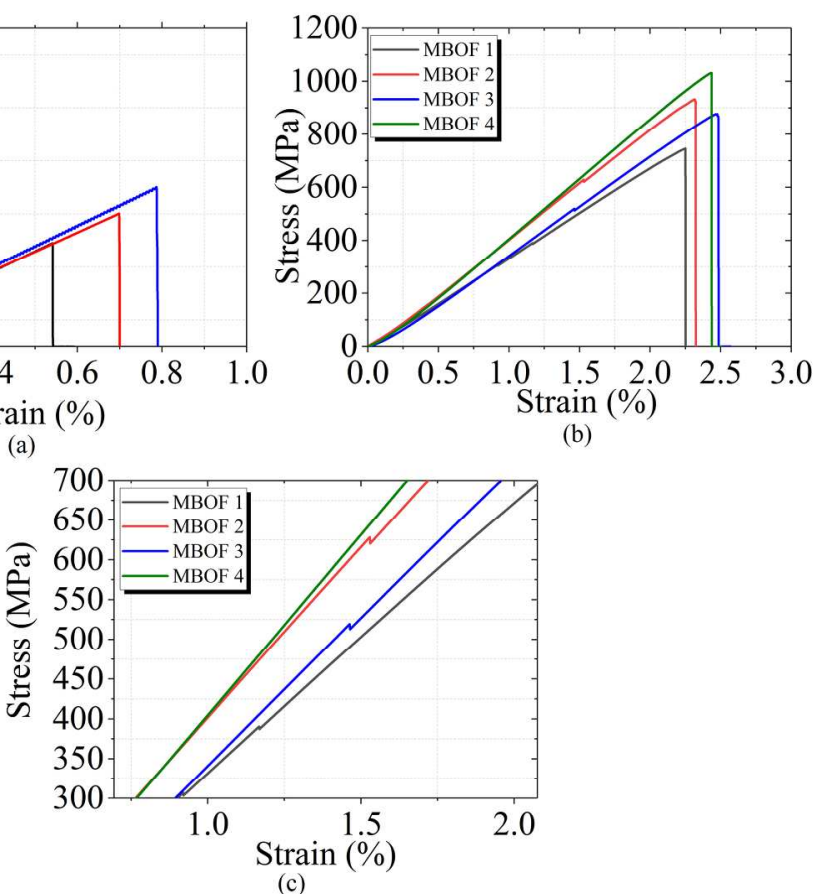

(c)

Figure 11. Stress vs strain curve for (a) Conventional optical fibre (OF) (b) Micro-braided optical fibre (MBOF) (c) Zoomed image of MBOF graph to describe the failure of the conventional optical fibre (OF) in the micro-braiding.

$202 \times 141 \mathrm{~mm}(300 \times 300$ DPI $)$ 


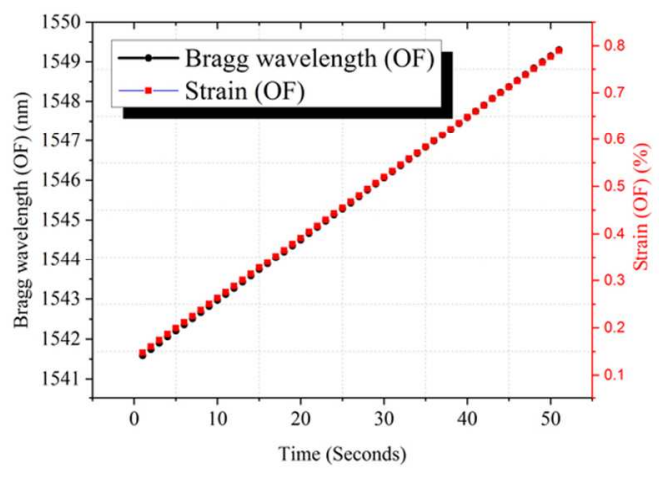

(a)

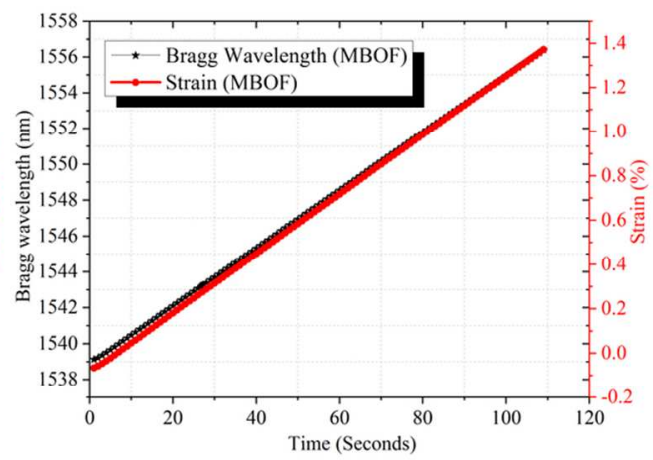

(b)

Figure 12. Plot of Bragg wavelength shift and strain as a function of time for (a) Micro-braided optical fibre (MBOF) (b) Conventional optical fibre (OF)

$$
95 \times 36 \mathrm{~mm}(300 \times 300 \mathrm{DPI})
$$



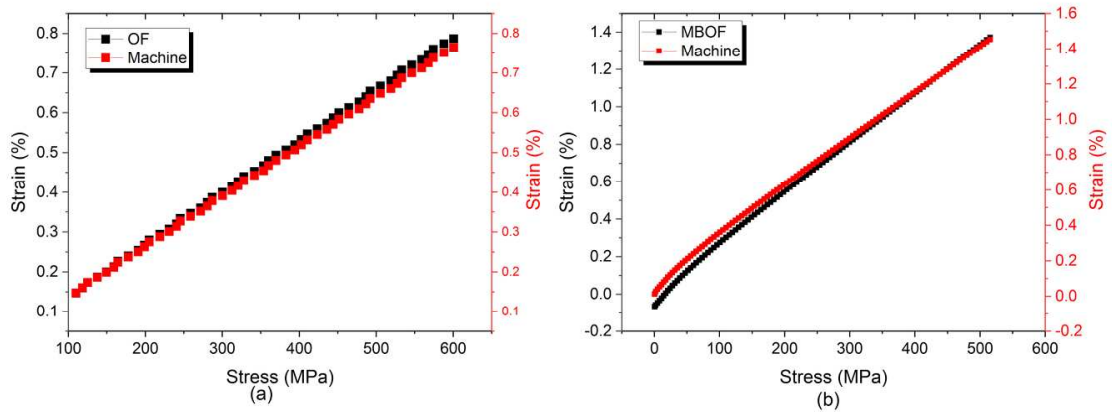

Figure 13. Graph of strain measured by the FBG interrogator and tensile machine for (a) conventional optical fibre (OF) and (b) micro-braided optical fibre (MBOF).

$202 \times 141 \mathrm{~mm}(300 \times 300$ DPI) 


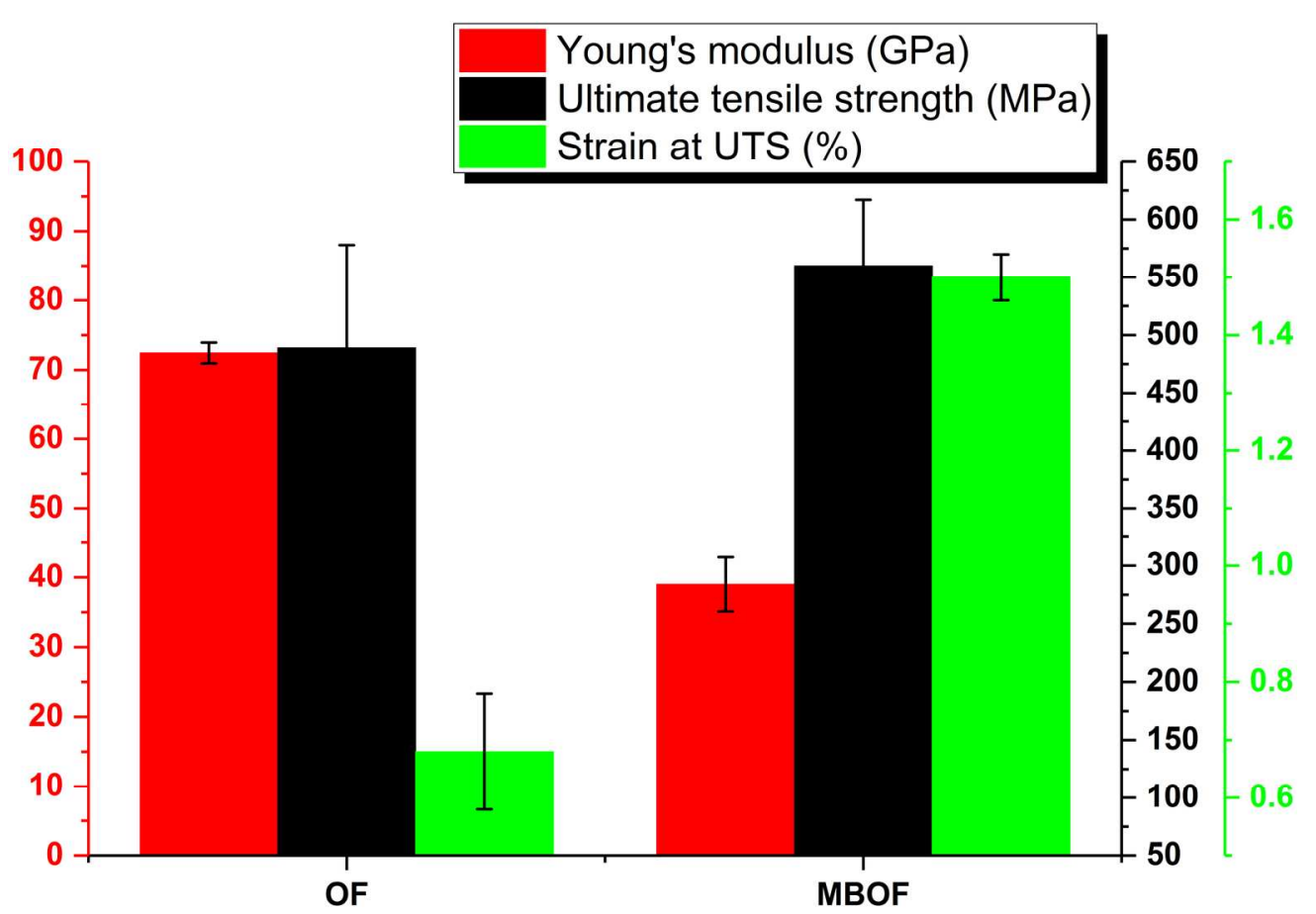

Figure14. Average values of Young's modulus, Ultimate tensile strength (UTS) and strain at strain at Ultimate tensile strength for micro-braided optical fibre (MBOF) and conventional optical fibre (OF).

$178 \times 123 \mathrm{~mm}(300 \times 300$ DPI $)$ 
Figure 15. Typical stress vs strain curve of (a) Braiding yarn (BY), (b) Conventional optical fibre (OF) and (c) Micro-braided optical fibre (MBOF).

$202 \times 141 \mathrm{~mm}(300 \times 300 \mathrm{DPI})$ 


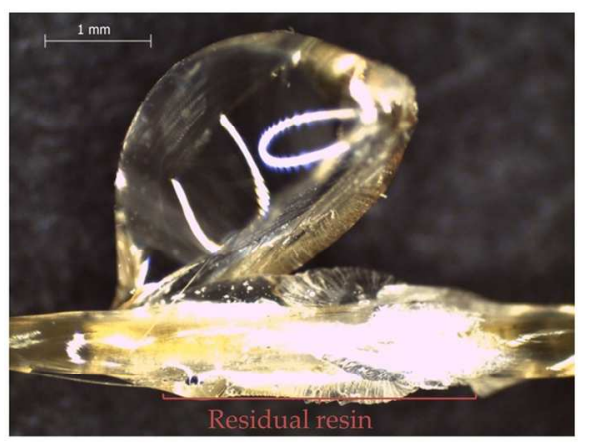

(a)

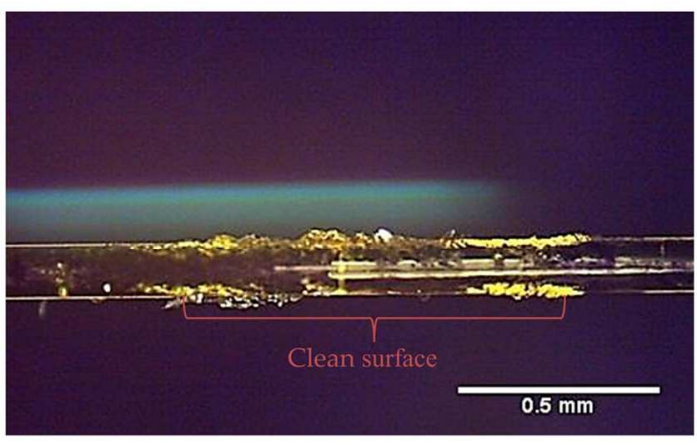

(b)

Figure 16. Optical image of (a) Micro-braided optical fibre (MBOF) showing residual resin after micro-bond test and (b) conventional optical fibre (OF) showing cleaner fibre surface.

$$
66 \times 25 \mathrm{~mm}(600 \times 600 \mathrm{DPI})
$$


Figure 17. Graph of De-bonding force vs embedded area of braiding yarn (BY), conventional optical fibre (OF) and micro-braided optical fibre (MBOF).

\section{8x159mm (300 x 300 DPI)}




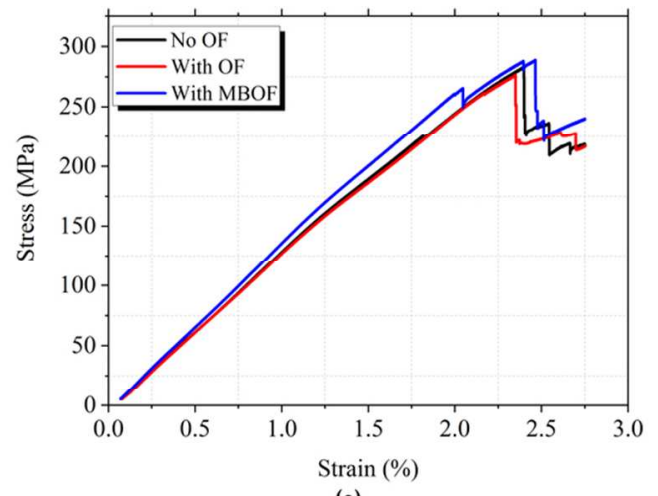

(a)

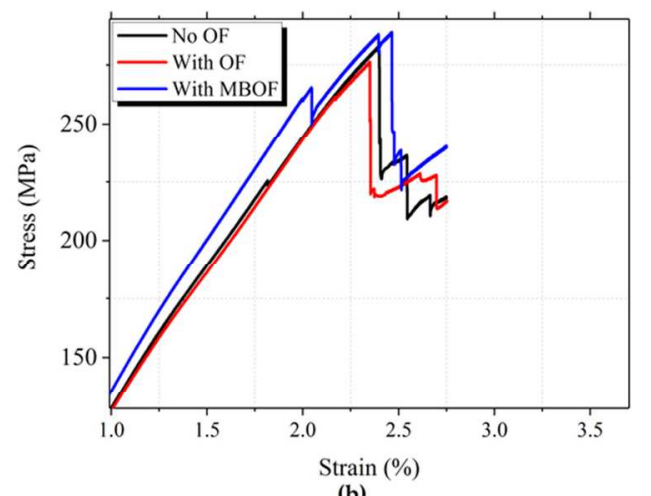

(b)

Figure 18. a) Typical Stress-strain curve of composite panel with no optical fibre, with optical fibre and with micro-braided optical fibre, (b) Zoomed image showing slippage.

\section{$92 \times 36 \mathrm{~mm}(300 \times 300 \mathrm{DPI})$}




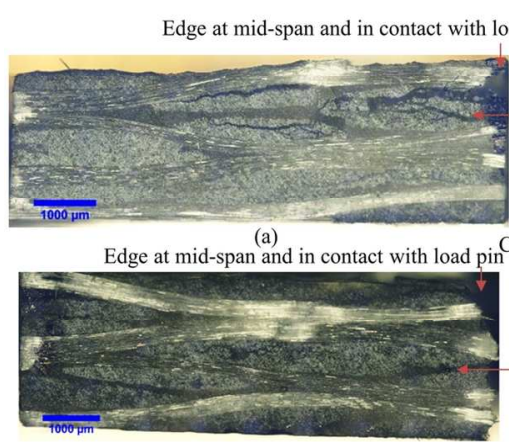

(c)

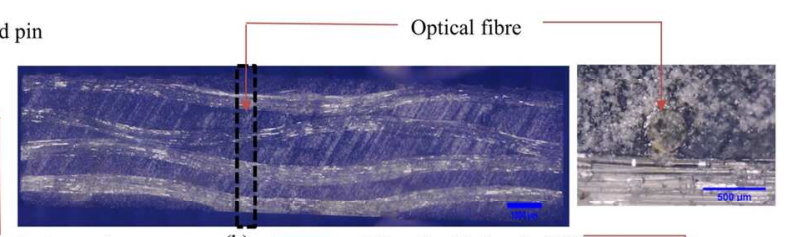

acks in matrix
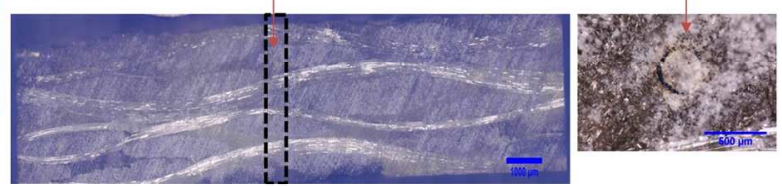

(d)

Figure 19. Micrograph of damaged composite sample after 3-point bending embedded with conventional optical fibre (OF) and micro-braided optical fibre (MBOF) (a) along the length for OF, (b) along the crosssection for OF, (c) along the length for MBOF and (d) along the cross-section for MBOF.

$142 \times 80 \mathrm{~mm}(300 \times 300 \mathrm{DPI})$ 
Figure 20. Average values of Ultimate flexural strength (UFS), Flexural modulus and strain Ultimate flexural strength for micro-braided optical fibre (MBOF) and conventional optical fibre (OF).

$182 \times 130 \mathrm{~mm}(300 \times 300 \mathrm{DPI})$ 